\title{
WINDOW OF OPPORTUNITY FOR SUSTAINABLE ENERGY
}

\author{
LAZAR GITELMAN, LARISA GITELMAN \& MIKHAIL KOZHEVNIKOV \\ Ural Federal University, Russia.
}

\begin{abstract}
The article considers the ways of increasing the sustainability of the energy sector in an unstable environment and technology modernization that implies radical structural transformations in the configuration of energy systems. The authors show that power engineering should be given a special emphasis in this context because it is the most stable branch of the energy sector in terms of its vulnerability to crisis. The article suggests that the processes of electrification that further technological progress and increase the innovative potential of a region's economy should be viewed as a driver forging a 'smart partnership' of power engineering and manufacturing. The authors analyze positive effects and price risks that emerge in the course of the implementation of electrification programs and use the analysis as a basis for their recommendations for developing regional electric power systems and effective relationships between utilities and consumers.

Keywords: Distributed generation, energy technology, electrification, sustainable energy, power engineering, window of opportunity.
\end{abstract}

\section{INTRODUCTION}

There is a variety of interpretations of the term 'window of opportunity'. The classical one is a concept of having boundaries of the acceptable array of publicly voiced opinions from the point of view of public morals [1]. Later studies defined the concept of 'window of opportunity' as a period of time (usually a fairly short one) when urgent decisions are implemented in order to eliminate a critical mass of problems [2-4].

Speaking of the subject of this article, the key issue being discussed is new opportunities for the modern energy sector and limitations that prevent the implementation of promising solutions. There is no doubt that the factors differ across countries and regions. In the Russian energy sector, for example, there are a number of opportunities such as:

- untapped potential for substituting electricity for other energy carriers in all branches of the economy, especially in manufacturing;

- big potential for the development of power engineering thanks to the state-sponsored policy of technology modernization of the economy (abundant fuel reserves, RES usage, solid scientific and technological expertise in the nuclear power industry, the expansive unified energy system of the country and consolidated energy systems in some regions).

At the same time, there are restrictions that make it difficult to embracing the opportunities. These include limited fuel reserves in some areas, environmental burdens, climatic conditions, an inefficient electric power market, an unfavorable ratio of prices for electricity and alternative energy carriers; poor electric connections between individual energy systems.

The issue of reliable electricity supply, of the access of countries, businesses and individuals to energy and energy services become ever more pressing and has turned into one of the most serious global problems. At the same time, "the window of opportunity" to change energy strategies at the inter-state, national and regional levels is still big enough [5]. Given the technological shifts that are taking place as part of the fourth industrial revolution (Industry 4.0) 


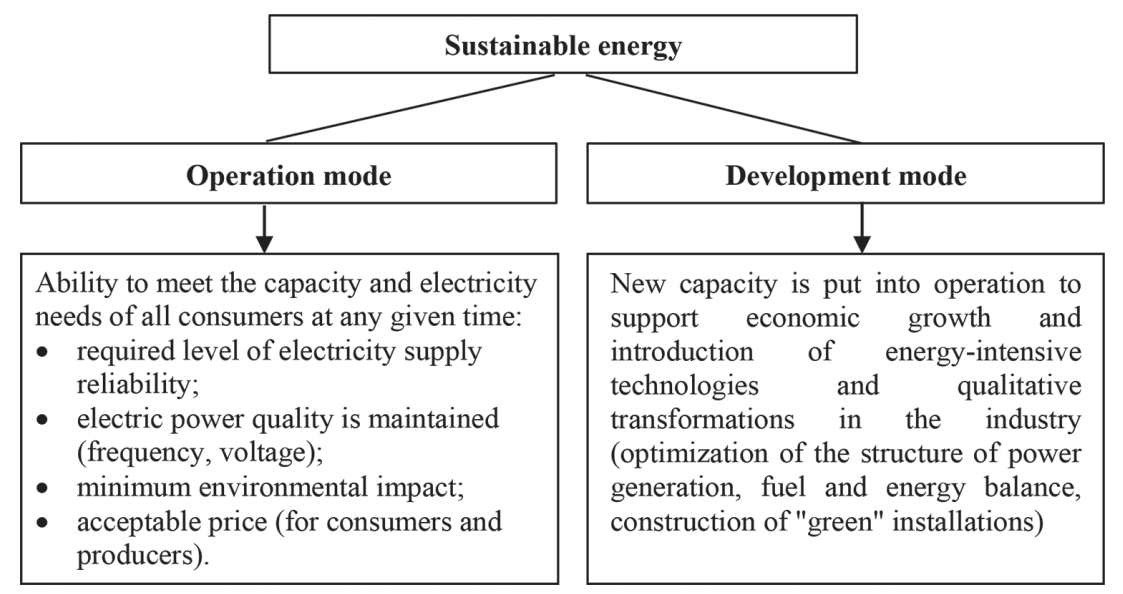

Figure 1: Sustainable energy: operation and development.

and the process of a technology overhaul in industry, it is extremely important to foresee the directions of the changes synchronized with the development of the energy sector.

The sustainability of electricity supply in a national economy is defined as the ability of energy industries to meet the current and future energy needs of the economy without disruptions and in full compliance with required volumes, structure and the set characteristics. This is necessary in order to support the running operations of fuel and energy consumers, to ensure economic growth, create social comfort (for households), to introduce energy-intensive technology innovations that are associated with structural shifts in end energy consumption (a higher level of electrification). Two sustainability modes of a power supplying organization are shown in Figure 1.

The sustainability of energy supply can be fully ensured if three conditions are met:

1. there is enough reserve capacity and the available stocks of energy carriers are sufficient;

2. energy prices are acceptable to both the suppliers (producers) and consumers;

3. the established standards and requirements of environmental safety and security of energy supply are complied with.

The sustainability of power supply in its broad interpretation can, therefore, serve as the foundation for maintaining and solidifying the energy and economic security of any state and, consequently, of its national security.

\section{MODERN CHALLENGES FACED BY ENERGY SECTOR}

When set in the global context, the sustainability of energy supply in the 21 st century is faced with a number of challenges that are fraught with threats to the economy and society. These can be divided into political, economic, environmental and workforce.

Today, the factor of politics plays a much bigger role in global prices of hydrocarbons. Geopolitical tensions and a lack of political stability in some countries and international relations lead to stronger volatility of global energy prices and abrupt changes in hydrocarbon supply logistics. This prompts countries to make sure that they have internal energy resources, which results in an interest in hard-to-recover reserves and ensuing unpredictable consequences for the environment. 
Economic threats stem, first and foremost, from the financial and economic crisis. Second, competitive energy markets with free pricing mechanisms (mainly in power engineering) that were recently established in many countries have all too often proven to be unable to align the economic interests of suppliers and consumers. Along with that, frequent cases of government interference in energy markets and changes to the rules of the market behavior in fact disoriented the market participants and external investors. Third, the emerging methods of hydrocarbon production have costs that are much higher than those of conventional technologies that determine global oil and gas prices today.

Countries are forced to adjust their environmental policies under political, public and populist pressure. In some countries, there is uncertainty about renewable energy sources (RES) and nuclear power that is further aggravated by volatile prices of hydrocarbons. It is not clear either how environmental restrictions will change in the long term. It has to be noted that the environmental effectiveness of some RES is in conflict with their economic advantages, which is hard to reconcile within the framework of market relations.

In terms of workforce issues, there is a growing shortage of highly qualified staff who is capable of addressing emerging tasks that are characterized with being nonlinear and requiring new knowledge. A potentially dangerous gap has appeared between the competencies of developers, new equipment makers and equipment users at the level of engineering teams and managers of energy companies. That stems from an oversight on the part of the professional education system that underestimated recent innovation and technological shifts in some branch of the energy sector. The problem is growing increasingly serious in emerging markets as well as in developed countries due to deficiencies in the training of engineers and managerial personnel with the required competences.

\section{FOCUS ON POWER ENGINEERING}

Within the context of the problem being considered in the article, we will place emphasis on power engineering. It is the backbone industry of the energy sector, the biggest consumer of hydrocarbon fuels and the key driver of progress in science and technology through the introduction of highly efficient yet, as a rule, energy-intensive innovations.

Power engineering is the most stable branch of the energy sector from the point of view of its vulnerability to the aftermath of crises. The sources of this stability are:

- Multiple development options and broad interchangeability between sources of energy and generators (type, capacity, primary energy resources):

- Multitier governance: the state, price and investment regulatory agencies, the electric system operator and its hierarchical structure;

- Strict rules and regulations that govern the creation and maintenance of reserve (generating and transmission) capacity;

- The integration of individual generators and microgrids into new-type electric power systems with physical and technological links.

Figure 2 shows a conceptual view of the future energy system of a region (based on [6, 7]).

The following managerial solutions are recommended for increasing the stability of power engineering and, consequently, the sustainability of power supply as a whole:

1. The development of 'smart' electric power systems that ensure an optimum self-regulating interaction between power-generating and power-consuming actors. 


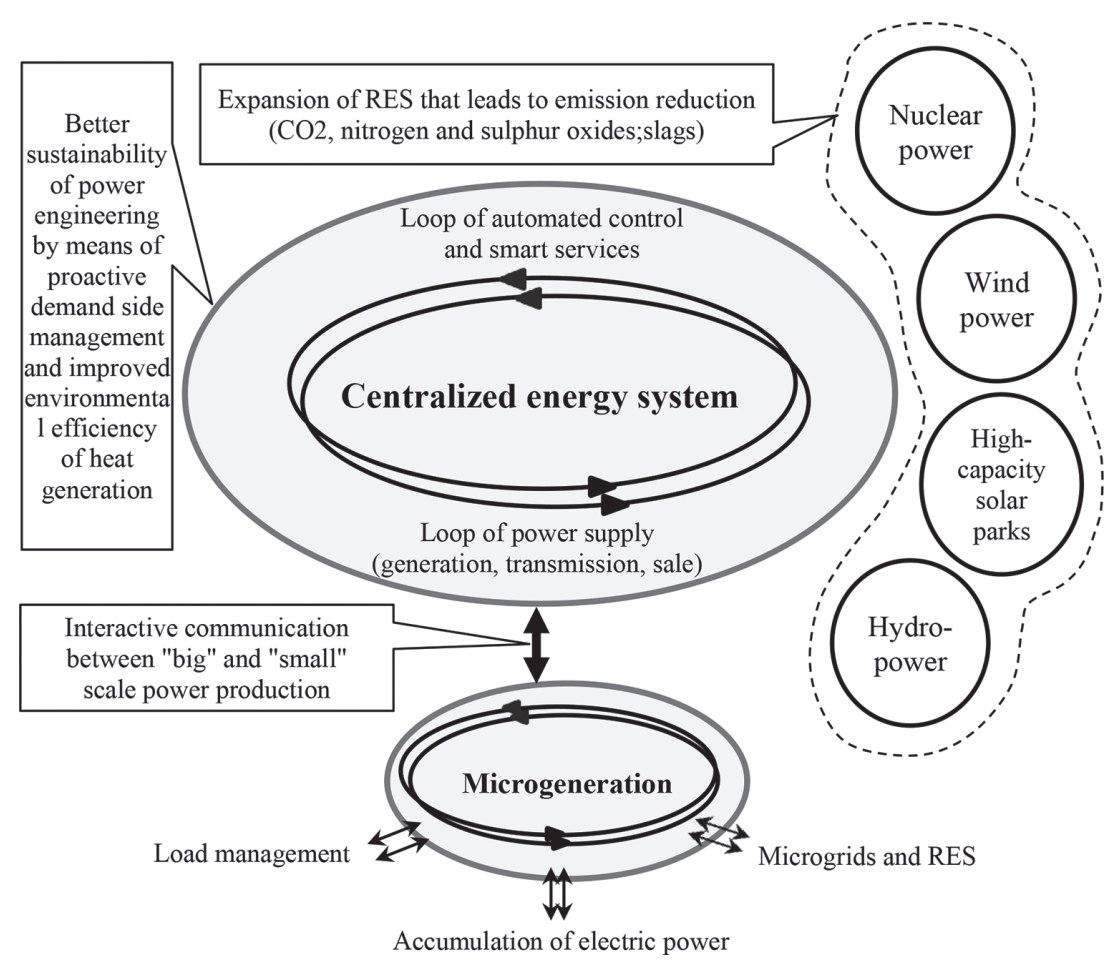

Figure 2: An outline of the future energy system of a region.

2. Structural fuel-saving shifts thanks to fewer thermal power plants and a correspondent increase in the share of ultra-safe new-generation NPPs and RES installations.

3. The adoption of cutting-edge scientific and technological solutions and organizational and technical measures at thermal power plants that are aimed at increasing the efficiency of thermodynamic cycles of power units and reducing per-unit fuel consumption. Priority here should be given to comparatively inexpensive solutions with a short payback period such as an upgrade of existing power-generating facilities and, in some cases, their retrofitting and the development of small-scale generation (small-scale hydropower plants, RES, small-scale CHP systems).

4. Creation of mechanism that enables energy companies to participate in energy conservation and energy efficiency programs in the consumer field.

There are two key ideas that need to be mentioned. The first one is demand-side management of capacity and electricity with an emphasis on optimum electricity use schedules [8]. The second one (and a highly relevant one too) is the substitution of electric power for high-quality fossil fuels considering growing prices of natural gas and fuel oil and uncertainty about the price dynamics in the near future. The properties of high-quality fuels are:

- their energy content $(\mathrm{kcal} / \mathrm{kg})$;

- the impact of their chemical composition (sulphur, ash, humidity) on the wear and tear of burners; 
- environmental characteristics;

- transport technology.

The main trend here is the changing structure of energy carriers in nearly all industries (including mass adoption of electric vehicles) with a growing share of electric power. In other words, we are witnessing a radical increase in electrification levels across the economy (a trend that has been clearly underestimated recently).

\section{NEW STAGE IN ELECTRIFICATION EXPANDS OPPORTUNITY}

Electrification could be defined as the introduction and uptake of technologies in which electrical power replaces alternatives (competing energy carriers) and generates more advanced final forms of energy, or is the only technologically possible energy carrier). The process of electrification under present conditions must be considered together with an innovative overhaul of production technologies in energy-consuming industries. For example, some metals treatment, heating and smelting technologies prohibit or make it difficult to use metalworking and traditional electric smelting (for example, in electric arc, induction and catalyst furnaces) due to specific characteristics of the feedstock, the complexity of the item being made and special product quality requirements. It is also important to take into account higher intensity and speed of the production process.

The prospects of a new stage of electrification depend, of course, on the cost of electric power supply. In a favorable environment that stems from, among other things, growing prices for fossil fuels (natural gas) and their limited availability to industrial consumers, one can foresee the following lines in industrial electrification:

- Electrothermic processes will completely replace fuel-based high-temperature and mediumtemperature methods of metal processing; some low-temperature processes will begin to be electrified (e.g., heating in some regions).

- Extensive application of electricity-based, physical and chemical materials-processing methods, the level of electrification reaching 50\% across the machine building industry [9].

- Pressing processes will be entirely powered by electricity (steam-driven presses and heavy-duty hammers will be phased out).

- New-generation smart electric automation devices will start to be adopted in various areas of corporate management.

Other examples here are highly effective methods of metals processing, heating and smelting technologies:

- spark eroding (electrical discharges);

- electron-beam processing (a beam of high-velocity electrons);

- plasma processing (low-termperature plasmas at Kelvin);

- ultrasonic processing (ultrasound ensures faster transfer of mechanical energy - for example, in metals processing ultrasound induces fast accelerations in abrasive particles).

The technological complexity, high-energy intensity and high cost of equipment limit the application of the above-mentioned technologies in manufacturing today to the required minimum. 
Technological progress in the world electronics industry, the energy and aerospace industries will lead to higher demand for costly high-quality feedstock and products that are made with the use of electricity-intensive technologies. Such unique technologies will become a crucial factor of competition in relevant global markets.

The technologies will also lay the strategic groundwork for an electricity-powered technology overhaul in metals manufacturing, machine building and the chemical industry. An example to be mentioned here is the chemical industry in the EU that planned to fully convert to electricity by 2050 (Fig. 3).

The roadmap of this large-scale project includes the following lines:

1. the use of electricity to upgrade heat and steam for efficient use in chemical processes (e.g., use of electric driven heat pump technology);

2. the use of electricity (electrolyzers) for direct chemical transformations, for example the production of hydrogen;

3. direct synthesis of intermediates and products using sustainable feedstock.

It is obvious that the expansion and intensification of electrification puts forth new multifaceted requirements to be met by power engineering and, more specifically, by regional energy systems. In this regard, is makes sense to consider the creation of 'electrification energy systems' as a model of the future. That means small and medium power-generating facilities (distributed generation). (This does not rule out the use of off-grid power generation options at companies provided that the conditions are right). These power-generating facilities are pulled together into local electricity systems that are sited in the closes proximity to consumers. The generators have the task of serving only the above-mentioned facilities being electrified. It is worth adding that the local energy systems must have backup reserve connections with the region's main grid.

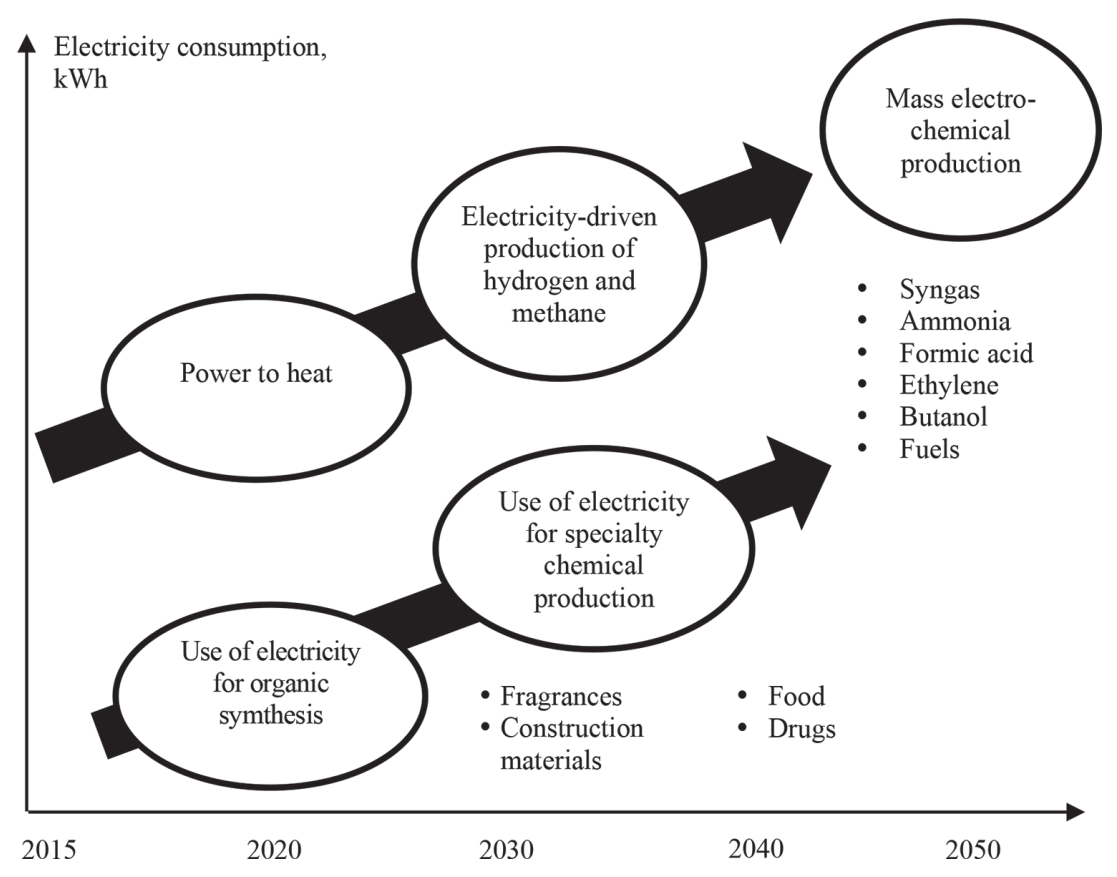

Figure 3: Roadmap for electrification of the European chemical industry [9]. 
There is a well-known technical and economic pattern: the higher the per-unit capacity of generators, the lower per-unit cost of a kilowatt of electricity they exhibit. There is, however, a possibility of considerably reducing the costs thanks to high flexibility of distributed energy resources (DER), the availability of turnkey equipment, the use of cheaper materials and replacement repair.

Other energy and economic advantages of distributed generation in the context of electrification (energy technology) are:

- Higher reliability and cost-effectiveness of electric power supply thanks to a reduced impact of the grid factor.

- Integration of projects aimed at the adoption of new technologies and development of the regional power engineering sector. This makes it possible to optimize the economic and energy parameters of each facility being electrified.

- Synchronization of the d launch of ready-to-operate power generating units with the adoption of electricity-powered processes at manufacturing companies.

- High-energy efficiency and low cost of small power-generating units (gas turbine plants and combined cycle plants, RES, small NPPs).

- The possibility of fully automated operation of generators that ensures the best performance from the energy, economic and environmental points of view.

The promising electricity-powered technologies that are listed above imply the operation of power plants with maximum capacity factors. This, in turn, brings down electricity generation costs. Small power plants are also highly flexible while being economic efficient, too.

\section{ECONOMIC EFFECTS OF ELECTRIFICATION}

An analysis of 120 countries conducted by the authors shows a consistent correlation between per-capita power consumption and the level of the country's economic development (Fig. 4).

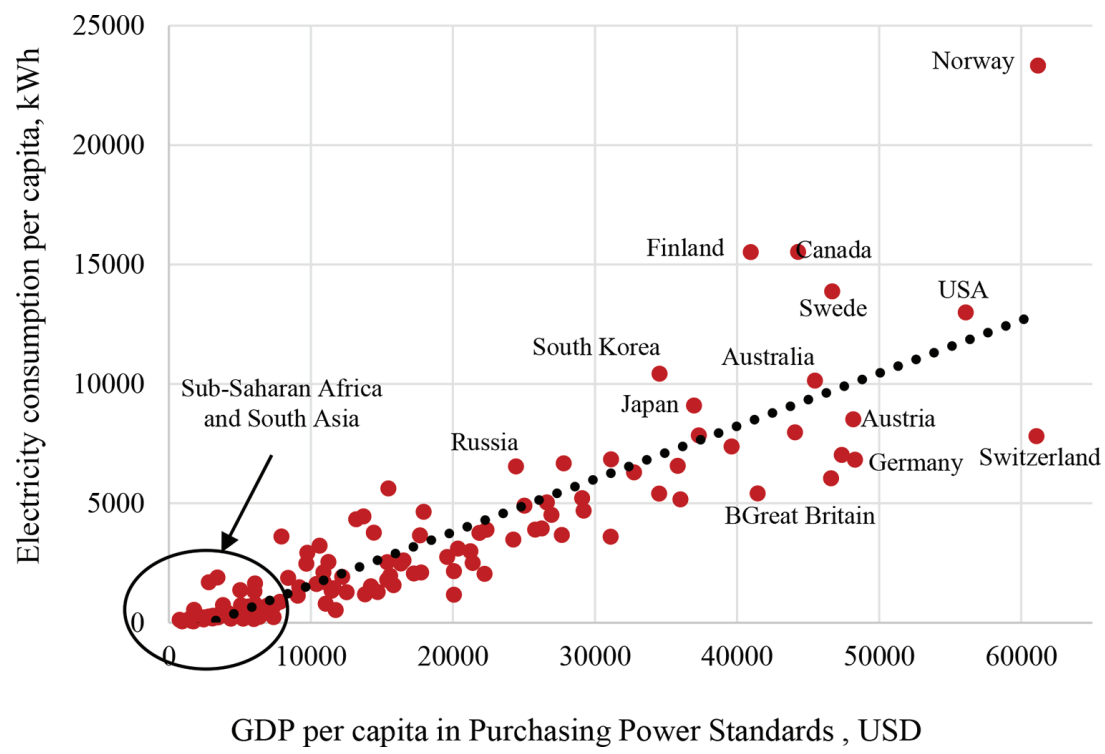

Figure 4: Graph of correlation between level of economic development and electrical power consumption in a region. 
For example, South Korea, the USA, Japan, Germany that ranked among the top five in Bloomberg's 2015 ranking of the world's 50 most innovative countries [10] are also the top five countries with the highest gross electrical power consumption and, with the exception of South Korea, are among the top 10 countries in terms of GDP. By contrast, the least electrified countries (Sub-Saharan Africa and South Asia) are also economic anti-leaders.

Of course, the correlation between the use of electricity and GDP per capita is an aggregated indicator and is not a precise reflection of societal well-being. However, in this analysis, it is acceptable to use this correlation (with a few reservations) because the question is not about living standards, but electrification levels. The ratio depends on three factors: the level of technological development in the given society; the structure of industry that determines the share of energy-intensive production processes (including obsolete ones), the level of energy efficiency.

The final economic effect of broad electrical power use is a sum total of various positive outcomes of electrification: new jobs, growth in adjacent markets, development of transport infrastructure, environmental improvements etc. Consequently, the impact of electrification on regional economics is multidimensional $[11,12]$. Figure 5 depicts in broad strokes the interrelation between electrification and economic growth.

In emerging economies where electrification programs primarily target suburban and rural areas, the key economic effects are the development of agriculture and commerce. The profitability of these business activities grows by 100-150\% [13, 14]. Manufacturing companies in developed countries report that the substation of electrical power for heat and other energy carriers in various production processes yields the following results in the long run:

- considerable improvement in operational, energy and environmental performance;

- lower cost of production;

- more flexibility when choosing locations for production facilities;

- faster development of innovations thanks to cutting-edge electro-chemical and electrophysical technologies [15-17].

In general, European industry, especially energy-intensive industries (production of steel, iron, cement, glass, chlorine, ammonia, petrochemical components) is projected to see its

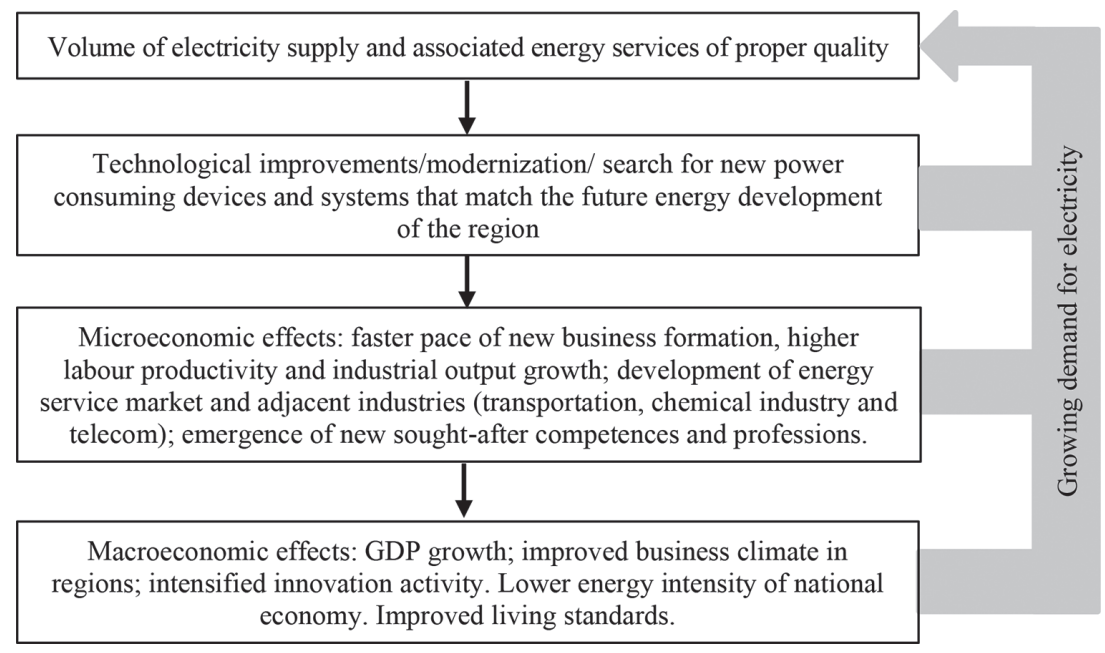

Figure 5: Decomposition of economic effect of electrification. 
electricity consumption grow approximately five-fold to 500 TWh by 2050 thanks to the spreading adoption of electro-thermal processes, electrolysis, plasma technologies, electrochemical technologies for hydrogen production. This will help reduce $\mathrm{CO}_{2}$ emissions fourfold to $85 \mathrm{Mt}$ a year [18].

The key effect of electrification for the energy sector is higher reliability of power networks and better load manageability thanks to the implementation of demand side management programs. It has to be noted, although, that higher electrification rates in industry (over 70\%) require the restructuring of the energy system - a transition from the concept of base load to an architecture built upon the principles of geographic, temporal and service flexibility [18].

\section{OFFSETTING 'PRICE HIKE' FOR SUSTAINABLE DEVELOPMENT}

Undoubtedly, the implementation of major electrification programs will cause a hike in electricity prices. It might be particularly painful to emerging economies where, as we know, the price of $1 \mathrm{kWh}$ (both for industrial consumers and households) is 10 to 20 times lower than, for example, in the USA and Great Britain [19]. In this context, it might be useful to mention a number of conceptual ideas and concrete mechanisms that could help offset the potential exponential growth in electricity prices.

1. Regional networks compensate for the inertia and risks of 'big' grids. Regional electrical power industries can implement investment projects with short payback periods that are aimed at the construction of highly efficient small and medium power plants with minimum investment risks. In order to attract investors they will need to have a guarantee of the rules of tariff regulation and stable supply of natural gas to appropriate power units.

The technical and economic parameters, size and location of the power plants are determined on the basis of energy programs and energy supply plans of cities and districts.

Under the present conditions, the priorities for building the regional network are:

- widespread installation of power generating units in boiler houses and the conversion of the latter into small-CHPs;

- retrofitting of CHPs by adding gas turbines;

- construction of new gas - fired and solid fuel combined cycle power plants;

- development of generators using locally available RES.

Within the regional network, small CHPs are deployed across the region and in the closes proximity to load centers to the extent of serving as off-grid generators. Among other things, they will be able to yield a capacity utilization factor exceeding $80 \%$. The concept will ensure the fastest possible commissioning of capacity almost in line with load growth, lower prices for energy and high reliability of power supply.

Of course, the creation of a regional network implies the engagement of not only electricity producers, but also energy infrastructure departments of manufacturing companies and independent energy producers. At the same time, the role of authorities and regional governments grows dramatically when it comes to working out an energy policy, forging a competitive environment at the stage of project and investment planning, coordinating the development of energy facilities that belong to different owners.

When speaking about interconnections between the regional network and the grid, it has to be noted the high investment mobility of the regional energy network makes it possible to overcome to a large extent the main drawback of the 'big' grid - its inertia. For example, regions might simultaneously build hundreds of power units while large NPP and thermal 
power plant projects are implemented as part of the 'big' grid.

2. The consumer only pays for the best possible solutions for the development of the electrical power sector. Competition among existing producers can restrain prices only if there is constantly available excess capacity. Otherwise, if the electricity balance is tight, marginal-cost pricing will result in a price hike.

When regulating electricity prices it is critical to make sure that prices are based on the future rather than past costs so that the existing tariffs don't restrict the projected effectiveness of investments in power engineering. On the contrary, tariffs should be set proceeding from the most economically sound solutions that are acceptable to potential investors.

It is, therefore, the projected operational costs of the project and the payback periods of the most efficient power plant projects that are appealing to private investors that should provide the basis for electricity prices. It is necessary to identify model (price-determining) power-generating facilities in each region that lead in terms of the technical and economic parameters prescribed by energy policy and that have been selected for construction as a result of investment project contests. The recommended maximum payback period for small and medium power plants (e.g., a megawatt-class gas turbine cogeneration plant) is 3 years. For big and costly grid-scale power plants, the payback period extends over 5-8 years (depending on type, installed capacity and mode). Additional regulatory efforts will, however, be needed in ordered to attract private investors. These include tax concessions, mode guarantees, and the government's participation in project funding. The longer the payback period times, the bigger concessions and government guarantees are needed to minimize investment risks. That calls for picking the most suitable options.

It has to be noted that the price of electricity generation in the big grid is generally higher than in the regional system. But the gap is bound to shrink gradually along with the growing price of natural gas that has a wider use in regional energy systems.

3. Energy efficiency is the consumer's responsibility. New consumers who do not have their own generating capacity should be required to meet tough energy efficiency standards as a mandatory condition of getting connected to the regional grid. If they don't, they should be charged a one-off fee for arranging the connection.

Other situations when consumers' funds could be used as investment in the development of the grid should be standardized, too. In this case, energy companies must stick to the principle of repayment of the funds received and must be held responsible to their targeted spending.

Industrial consumers who have their own generating capacity should have unrestricted free access to the regional power system to be able to sell electricity in the competitive market provided that such connection won't diminish the reliability of power supply for other consumers.

4. Investment in electricity consumption replace investment in electricity production. The utility's relations with consumers as part of demand-side management programs prove to be a highly effective price restraint.

The essence of 'demand-side management' is that part of the funds being invested is redirected from commissioning new capacity to improving energy efficiency on the consumer's side. Demand-side management addresses the following key issues:

- reducing the need for investment in new power plans and transmission lines;

- higher reliability of power supply; 
- restraining prices for new consumers (it is a known fact that it costs three to five times less to save $1 \mathrm{kWh}$ than to produce one extra kilowatt*hour, while payback periods of investments in energy saving projects are four to five times shorter than in the construction of a new power plant);

- improving the environmental profile of the area.

As a result, there is a balance of interests among the energy supplier, consumers and the region as a whole, and energy companies improve their competitive position, too.

5. Tax regulations. Taxes on the industry should be reduced in view of the future expansion of the tax base in the economy due to faster economic growth and an economic effect from broader electrification and lower electricity prices. The measure should be applied to big grid facilities in the first place ahead of the launch of capital-intensive powergenerating facilities.

Of course, we are far from thinking that electricity prices can be prevented from growing: prices will grow for the sole reason of growing fuel prices and inflation. But the pace of the growth should and can be restrained making the price dynamics truly controllable.

\section{CONCLUSION}

Providing access to energy and ensuring sustainable, safe and environmentally friendly power supply is a fundamental problem of the 21 st century. At the heart of it is power engineering that is directly involved in industrial electrification across all sectors of the economy. It is power engineering that has the capabilities making it better equipped than other energy industries for managing sustainability and acting as the driver of progress in science and technology, thus considerably expanding the corridor of opportunity for implementing innovative solutions.

This study brings to the fore the problem of a new stage of electrification that is associated with the rapid smartization of all economic sectors and the need for promptly introducing advanced energy technologies, services and organization mechanisms. This adds even more weight to the task of furthering integration of big businesses, universities, research centers, financial and legislative institutions in order to create conditions, instruments and competencies that are requirement for passing through the 'window of opportunity' with a success. The implementation of the recommendations proposed by the authors will increase the effectiveness of electrification and make the development of the energy sector and associated energy consuming systems more sustainable.

\section{ACKNOWLEDGEMENT}

The work was supported by Act 211 Government of the Russian Federation, contract № 02.A03.21.0006.

\section{REFERENCES}

[1] Lehman, J., A brief explanation of the overton window. Available at: http://www.mackinac.org/overtonwindow. (accessed February 07, 2016).

[2] Birkmann, J., Buckle, P., Jaeger, J., Pelling, M., Setiadi, N., Garschagen, M., Fernando, N. \& Kropp, J., Extreme events and disasters: a window of opportunity for change? Analysis of organizational, institutional and political changes, formal and informal responses after mega-disasters. Natural Hazards, 55, pp. 637-655, 2010.

https://doi.org/10.1007/s11069-008-9319-2 
[3] Ashford, L.S., Smith, R.R., De Souza, R.-M., Fikree, F.F. \& Yinger, N.V., Creating windows of opportunity for policy change: incorporating evidence into decentralized planning in Kenya. Bulletin of the World Health Organization, 84(8), 2006, pp. 669-672. https://doi.org/10.2471/blt.06.030593

[4] Doeser, F. \& Eidenfalk, J., The importance of windows of opportunity for foreign policy change. International Area Studies Review, 16(4), pp. 390-406, 2013. https://doi.org/10.1177/2233865913512117

[5] Ashby, W.R., An introduction to cybernetics, First Edition, London: Chapman and Hall, New York, NY: John Wiley and Sons, 1956.

[6] Ota, U., Taniguchi, H., Nakajima, T., Liyanage, K.M., Baba, J. \& Yokoyama, A., Proposal of smart storage for ubiquitous power grid. IEEJ Transactions on Power and Energy, 11(130), pp. 989-994, 2010.

https://doi.org/10.1541/ieejpes.130.989

[7] Coping with the Energy Challenge. The IEC's role from 2010 to 2030. Smart electrification - The key to energy efficiency. White Paper. International Electrotechnical Commission, 2010. Available at: http://www.iec.ch/smartenergy/pdf/white_paper_lres.pdf. (accessed February 07, 2016).

[8] Gitelman, L.D., Ratnikov, B.E. \& Kozhevnikov, M.V., Demand-side management for energy in the region. Economy of Region, 1, pp. 71-77, 2013.

[9] Electrification of Chemical Industry. An opportunity for the chemical and electricity sector, available at: https://www.tno.nl/media/5813/electrification_of_chemical_industry.pdf. (accessed February 07, 2016).

[10] The Bloomberg Innovation Index 2016. Available at: https://www.bloomberg.com/ graphics/2015-innovative-countries/. (accessed February 07, 2016).

[11] Technology Outlook 2025 - The 10 technology trends creating a new power reality, Arnhem: DNV GL, 2016.

[12] Otsuka, A., Regional energy demand and energy efficiency in Japan. An application of economic analysis, Springer International Publishing, 2017.

https://doi.org/10.1007/978-3-319-47566-0_1

[13] Imai, K. \& Palit, D., Impacts of electrification with renewable energies on local economies: the case of India's rural areas. The International Journal of Environmental Sustainability, 9, pp. 3-20, 2013. https://doi.org/10.18848/2325-1077/cgp/v09i02/55082

[14] Limscomb, M., Mobarak, A.M. \& Barham, T., Development effects of electrification: evidence from the topographic placement of hydropower plants in Brazil. American Economic Journal: Applied Economics, 5(2), pp. 200-231, 2013. https://doi.org/10.1257/app.5.2.200

[15] Tracking the trends 2016. The top 10 issues mining companies will face in the coming year. Deloitte's White Paper, 2016. Available at: https://www2.deloitte.com/ content/dam/Deloitte/global/Documents/Energy-and-Resources/gx-er-tracking-thetrends-2016.pdf. (accessed February 07, 2016).

[16] Kranenburg, K., Schols, E., Gelevert, H., De Kler, R., Delft, Y. \& Weeda, M., Empowering the chemical industry. Opportunities for electrification, TNO - ECN Report, 2016. Available at: https://www.tno.nl/media/7514/voltachem_electrification_whitepaper_2016.pdf. (accessed 07 February, 2016) 
[17] Ragazzi, M., Ionescu, G. \& Cioranu, C.I., Assessment of environmental impact from renewable and non-renewable energy sources. International Journal of Energy Production and Management, 1(2), pp. 8-16, 2017. https://doi.org/10.2495/eq-v2-n1-8-16

[18] Lechtenbohmer, S., Nilsson, L.J., Ahman, M. \& Schneider, C., Decarbonising the energy intensive basic materials industry through electrification - Implications for future EU electricity demand. Energy, 115, pp. 1623-1631, 2016.

https://doi.org/10.1016/j.energy.2016.07.110

[19] The Handbook of Global Energy Policy, ed. Andreas Goldthau, Oxford: John Wiley \& Sons Ltd, 2013, 566 p. 